\title{
Application of Electric Generators Driven by Tractor in Agriculture
}

\author{
Mr. Mohammad Hakim Osmani \\ Assistant Professor in Department of Agronomy, \\ Agriculture Faculty of Kabul University, Afghanistan
}

\begin{abstract}
The problems of generating sets powered by the tractor for the backup power supply of the agricultural production of small and medium energy build up. The comparative characteristics of expenses on diesel power plants and electricity generation systems, when the backup power supply of dairy farms. Justify the need for power plant agriculture.
\end{abstract}

Keywords: Agriculture, Backup power supply, Power generator, Power take-off shaft of the tractor, reduced costs, Damages

\section{Introduction:}

The development of a market economy is increased requirements for uninterrupted power supply of agricultural production. Interruptions in electricity applied to agriculture substantial material damage and disrupt the course of technological processes [1, 2, etc.].

To improve the reliability of power supply, it is desirable to use network backup. However, it does not always provide uninterrupted power supply, especially in adverse weather conditions (ice, high winds, etc.). In addition, the majority of rural consumers of Kazakhstan removed at considerable distances and provided with electricity by the radial transmission lines of considerable length, making it difficult to use network backup.

Therefore, at this stage of development of rural electricity, it is advisable to develop both traditional and non-traditional sources of energy autonomous.
Budding is the use of alternative energy sources, among which are of particular interest for Kazakhstan are: wind, solar and small hydro. However, these sources of energy have not yet received proper distribution due to the complexity of the technical and economic decisions [2].

Currently, when a power interruption, as a basic stand-alone power source, and used diesel power generating sets (DES), mobile power plants (TPP) and power generators driven by the PTO of the tractor (EGT). Considered in this paper setting EGT developed in the Kazakh National Agrarian University (KazNAU).

Figure 1 shows a general view of the apparatus EGT, which consists of an electric generator with a control panel mounted on a metal frame.

The rotation of the electric generator is provided by the PTO shaft (PTO) of the tractor via a drive and Vbelt transmission. EGT Mounts provide an easy way to connect them with the levers linkage common tractors (MTZ-80, MTZ-82, DT-75, T-150K, etc.) and transported over various distances. Vehicle condition EGT is shown in Figure 2.

To use the EGT at remote agricultural sites proposed structural improvements, which aim to create a universal installation capable ensure prompt repairs in the field. For this purpose, in the upper part of the frame formed compartments which may be placed power tools for repairs. At the bottom there is enough space for welding machines, battery chargers and 
earthling. Shield EGT control is equipped with a three-phase and single-phase outputs.

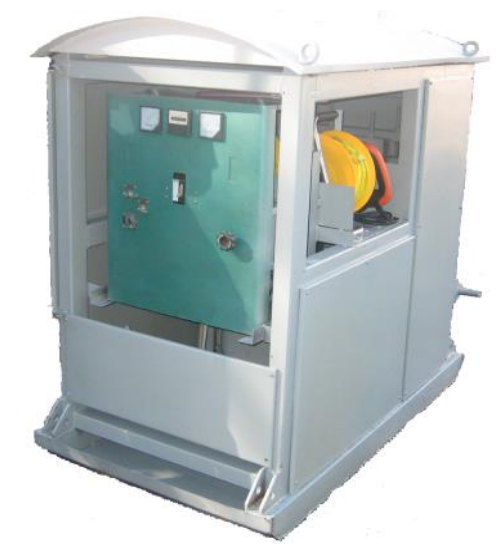

Figure 1 - EGT Construction

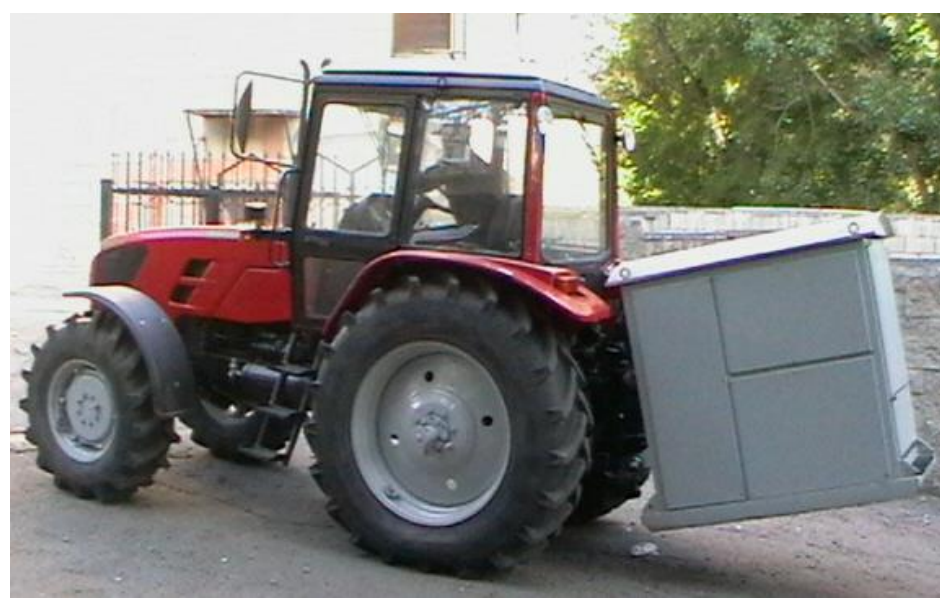

Figure 2 - EGT in transport position

Installation starts from the moment when the tractor PTO (power take off shaft) and bring his speed about $1000 \mathrm{rev} / \mathrm{min}$. After that starts the generator and the control room equipment show the relevant data.

Connecting the electrical load must be accompanied by the regulation and maintenance of the rated voltage and frequency. The first is governed by the handle on the control panel, the second - the tractor engine speed.

Under normal conditions, electricity consumer groups of EGT via the existing distribution points, cabinets or panels.

If you change the place of work EGT rises via the tractor hydraulics and transported to the required distance. When long-distance transportation of installation immersed in the trailer or the car body.
Thus, the proposed EGT simple in execution and maintenance, mobile, reliable in operation and does not require special storage facilities. As the power generator can be used, new and second-hand (available in farms) synchronous generators of different brands and types without design changes.

Application backup independent source would be economically justified if the annual costs given to it will be equal to or less than the expected annual damage from power outages:

$$
\mathrm{W} \leq \mathrm{V}(1)
$$

Where $\mathrm{V}$ - the total annual damage in agricultural production from power interruptions, tengeyear.

The effectiveness of the use of reserve power supply of DES during breaks large objects livestock and poultry proved in a number of references $[1,2$, etc.].

However, now in the agriculture of Kazakhstan functioning set of livestock small and medium sized farms (dairy farms with 400 cows or less, for cattle fattening farm for 6000 heads and smaller, and the like), which produced most of the agricultural products $[1,2$, etc. $]$.

For these farms small and medium power condition of the effectiveness of backup (1) of the ECT, in most cases impossible, since a relatively small value of the total annual damage caused by interruptions in the centralized power have not always compete with standalone redundancy costs. For example, in Figure 3 shows the dependence of the average damage to the dairy farm (ITF) for 200 cows and reduced annual costs for the installation of stationary diesel power station and EGT $30 \mathrm{~kW}$ of varying lengths for the year electricity supply interruptions.

Damage to agricultural production by power outages on the farm under consideration is determined by the method of [3]. This approach is applicable to the determination of damage to agricultural facilities low power, since their manufacturing processes are typically relatively short mode. 


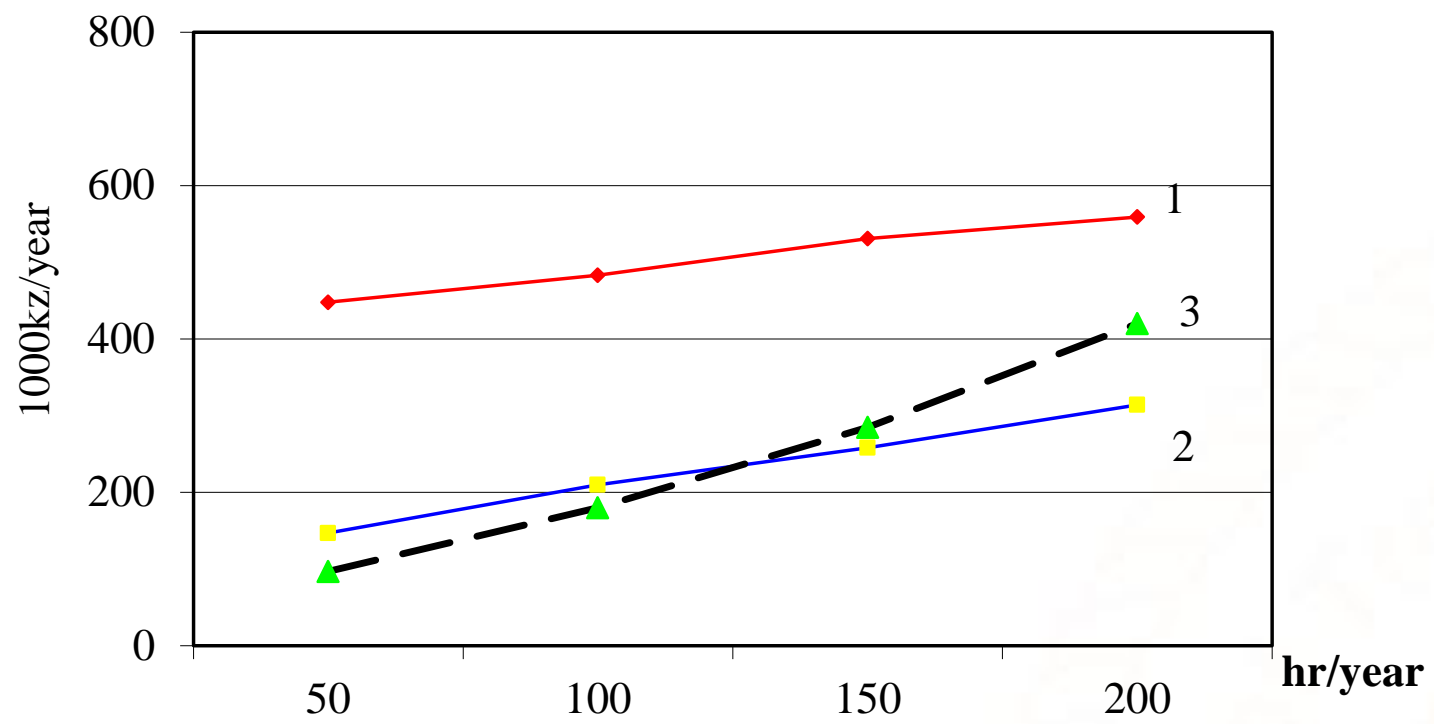

Figure 3 - Dependence of reduced annual costs of DES and EGT

$30 \mathrm{~kW}$ of power interruption time:

1- for the DPP; 2 - HRT; 3 - average damage MTF for 200 cows

Comparison of dependencies in Figure 3 shows that the average duration of different outages effectiveness of EGT is reached at about 100 hours or more, and the installation of stationary diesel power station on the MTF for 200 cows is economically inexpedient.

A similar comparison of such indicators for the TFM 400 cows (Figure 4) shows that the effectiveness of EGT is reached when the average duration of power interruption of about $70 \ldots 80$ hours, and stationary diesel power station - at 180 hours or more.

Given that the average duration of most farms is 150 hours $[4,5$, etc.], It is easy to verify the effectiveness of EGT driven tractors for many agricultural enterprises.

The effectiveness of the autonomous redundancy will increase significantly when using mobile autonomous energy sources, as these sources during a power interruption; you can reserve several agricultural facilities of low power. This contributes to the relatively short-term operation of agricultural power consumers.

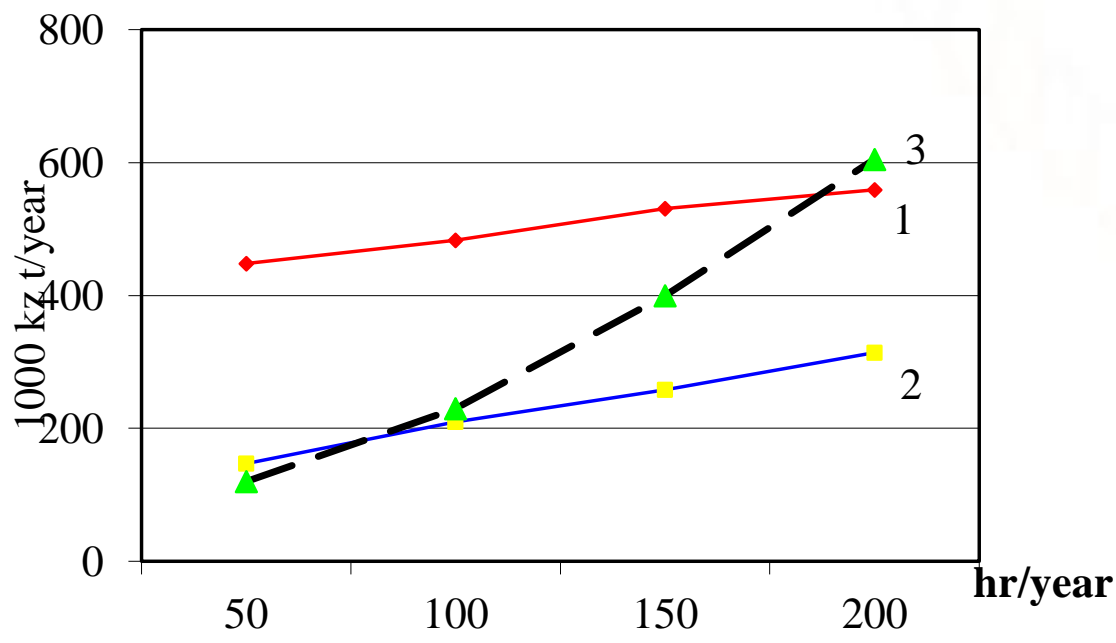


Figure 4 - Dependence of reduced annual costs of DES and EGT

جنر انور نوع ديزلى=

EGT =

$30 \mathrm{~kW}$ of power interruption time:

1 - for the DPP; 2 - for Euchar; 3 - average damage MTF for 400 cows.

Technical and economic calculations have shown that the annual costs given for EGT is about 3 times lower than for fixed or mobile DEL similar capacity. It was found that the payback period EGT does not exceed 1 year. This is due to the fact that EGT is not permanently fixed to the prime mover and the tractor is only required at the time of backup power responsible consumers.

Given the above considerations, it can be concluded that the most effective means of autonomous redundant agricultural buildings is the use of lowpower EGT. Additionally, EGT drive from the tractor eliminates the generator start-up problem in winter time and significantly reduces the cost of maintenance and installation services.

\section{REFERENCES:}

1) Budzko IA, Suhl NM Power Supply of Agriculture. - M.:Agropromizdat, 1990.-496 p.

2) Umbetkulov EK The use of generators driven by tractors Backup power supply of dairy farms. Materials Intl. Scientific-practical conference. Almaty. KazNAU, April 17-18, 2008.

3) Guidelines for the determination of the damage caused by a power outage agricultural predpriyatiyam. M .: VIESH, 1983, 96 p.

4) Fedossenko RJ, AJ Melnikov The operational reliability of electric agricultural naznacheniya. M.: Energy, 1977.- 320 p.

5) Agalarov AM, Suhl NM, NF Molosnov Evaluation of reliability of agricultural machinery elektrosnabzheniya.-agricultural hozyaystve.1970, №3, p.40 ... 42 . 